\title{
PENGARUH SUHU QUENCH DAN TEMPER PADA PROSES PENGERASAN PERMUKAAN BAJA AISI 1045
}

\author{
Miftah Azizi, Helmy Purwanto dan Muhammad. Dzulfikar \\ Jurusan teknik mesin, Fakultas teknik, universitas wahid hasyim semarang \\ Jl. Menoreh tengah X/22, Sampangan, Semarang 50236 \\ *Email: azizimiftah@gmail.com
}

\begin{abstract}
Abstrak
Perlakuan panas (heat treatment) didefinisikan sebagai kombinasi operasi pemanasan dan pendinginan yang terkontrol dalam keadaan padat untuk mendapatkan sifat- sifat tertentu pada baja. Salah satu metode perlakuan panas yaitu proses quenching dan tempering dengan mesin pemanas induksi. Penelitian kali ini bertujuan untuk mengetahui kekerasan, struktur mikro dari pin track link bulldozer dan untuk mengetahui pengaruh temperatur tempering pasca quenching dengan media air pada baja AISI 1045 terhadap struktur mikro dan kekerasan menggunakan mesin pemanas induksi dengan variasi temperatur quenching dan tempering. Hasil pengujian kekerasan spesimen pin track link bulldozer dari tepi ke tengah spesimen mengalami penurunan. Nilai rerata pada tepi spesimen jarak $1 \mathrm{~mm}$ adalah 50,5 HRC, pada jarak $14 \mathrm{~mm}$ dari tepi spesimen memiliki nilai kekerasan $28 \mathrm{HRC}$, struktur mikro memperlihatkan martensit pada tepi ferrite dan pearlite pada tengah spesimen. Sedangkan pada baja AISI 1045 kekerasan maksimum setelah mengalami proses quenching adalah 61,5 HRC dan setelah proses tempering mengalami penurunan yaitu sebesar 49 $H R C$, struktur mikro memperlihatkan martensit ditepi spesimen uji dan ferrite-pearlite pada tengah spesimen uji.
\end{abstract}

Kata kunci: perlakuan panas, pemanas induksi, uji kekerasan, struktur mikro

\section{PENDAHULUAN}

Seiring dengan perkembangan yang semakin maju, mendorong para pelaku dunia industri untuk meningkatkan kebutuhan penggunaan dari hasil pengerasan baja yang dibutuhkan konsumen. Pengerasan permukaan merupakan pengembangan dari perlakuan panas konvensional dimana bagian yang mengalami perlakuan hanya terbatas pada bagian permukaan saja. Salah satu metode pengerasan permukaan (surface hardening) yang dapat diterapkan untuk meningkatkan kekerasan permukaan bahan adalah metode induksi magnetik. Pengerasan dapat dilakukan dengan cara quenching. Quenching adalah memanaskan benda kerja hingga temperatur austenisasi dilanjutkan dengan proses pencelupan di dalam media pendingin.

Proses quenching menghasilkan produk yang keras, getas dan terdapat tegangan sisa Untuk mengurangi kekerasan, kegetasan dan menghilangkan tegangan sisa maka perlu dilakukan proses tempering. Tempering merupakan suatu proses pemanasan baja hingga mencapai temperatur dibawah temperatur kritis dan menahannya pada temperatur tersebut untuk jangka waktu tertentu. Ketahanan aus didefinisikan sebagai ketahanan terhadap abrasi atau ketahanan terhadap pengurangan dimensi akibat suatu gesekan. ketahanan aus berbanding lurus dengan kekerasan (Avner, 1974).

Bulldozer adalah jenis peralatan berat bertipe traktor yang menggunakan track atau rantai serta dilengkapi dengan pisau atau blade yang terletak di depan. Undercarriage bulldozer merupakan komponen bagian bawah dari unit bulldozer Track link berfungsi untuk merubah gerakan putaran menjadi gerakan gulungan. Salah satu komponen yang terdapat pada track link adalah pin. Pin track link berfungsi menghubungkan dan memutuskan link satu dengan link berikutnya juga sebagai tempat kedudukan bushing. Bentuk Undercarriage bulldozer dapat dilihat pada Gambar 1.

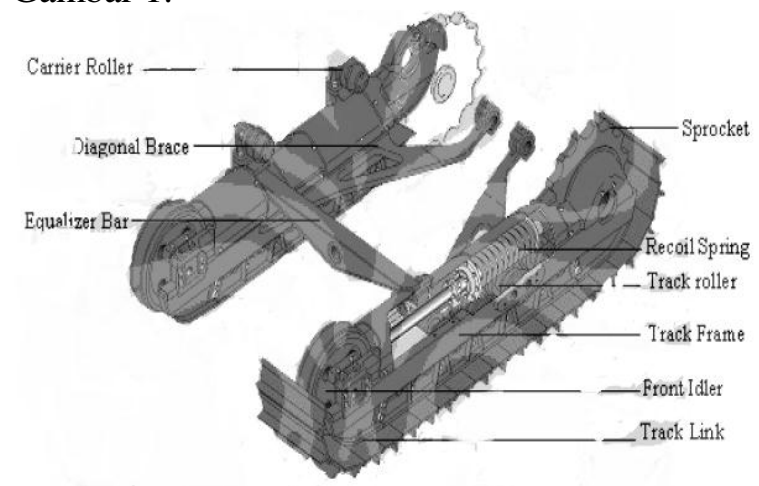

Gambar 1. Komponen undercarriage bulldozer 


\section{Perlakuan Panas (Heat Treatment)}

Perlakuan panas (heat treatment) adalah suatu proses mengubah sifat mekanis logam dengan cara mengubah struktur mikro melalui proses pemanasan dan pengaturan kecepatan pendinginan dengan atau tanpa mengubah komposisi kimia. Tujuan proses perlakuan panas untuk menghasilkan sifat-sifat logam yang

diinginkan.

Quenching merupakan pendinginan secara cepat suatu logam dengan pencelupan pada media pendingin.Kekerasan maksimum dapat terjadi dengan mendinginkan secara mendadak sampel yang telah dipanaskan sehingga mengakibatkan perubahan struktur mikro.

Tempering merupakan suatu proses pemanasan baja hingga mencapai temperatur dibawah temperatur kritis dan menahannya pada temperatur tersebut untuk jangka waktu tertentu. Kemudian baja tersebut didinginkan dengan menggunakan media udara.Proses tempering ini bertujuan untuk memperoleh keuletan dan ketangguhan pada sifat baja. Proses tempering biasa diterapkan terhadap baja yang telah mengalami proses quenching, atau celup cepat (Thelning K.E, 1984).

\section{Prinsip pemanasan induksi}

Prinsip pemanasan induksi secara sederhana yaitu ketika sebuah kumparan yang dialiri arus bolak-balik berada disekitar bahan konduktif, maka keduanya akan dihubungkan oleh medan magnet bolak-balik. Medan magnet ini akan menginduksikan arus listrik bolakbalik yang disebut arus $e d d y$, yang mengalir pada permukaan bahan konduktif dan kemudian akan memanaskan bahan konduktif tersebut. Jadi secara umum prinsip dasar yang dimanfaatkan dalam pemanasan induksi yaitu:

- Arus Eddy memiliki peranan yang paling dominan dalam proses pemanasan induksi. Panas yang dihasilkan pada material sangat bergantung kepada besarnya arus eddy yang diinduksikan oleh lilitan penginduksi. Ketika lilitan dialiri oleh arus bolak-balik, maka akan timbul medan magnet di sekitar kawat penghantar. Medan magnet tersebut besarnya berubah-ubah sesuai dengan arus yang mengalir pada lilitan tersebut.

- Efek kulit jika arus searah melewati sebuah konduktor, maka arus akan terdistribusi secara merata pada seluruh permukaan konduktor tersebut. Tetapi jika arus bolak- balik dialirkan melalui konduktor yang sama, arus tidak tersebar secara merata. Kerapatan arus paling besar selalu berada di permukaan konduktor dan kerapatan arus ini akan semakin berkurang ketika mendekati pusat konduktor. Efek kulit ini menyebabkan energi panas yang dikonversi dari energi listrik terpusat pada permukaan material, sehingga permukaan material lebih cepat panas dari pada pusatnya.

\section{METODOLOGI}

Alat

Peralatan utama yang digunakan adalah:

Alat pemanas induksi

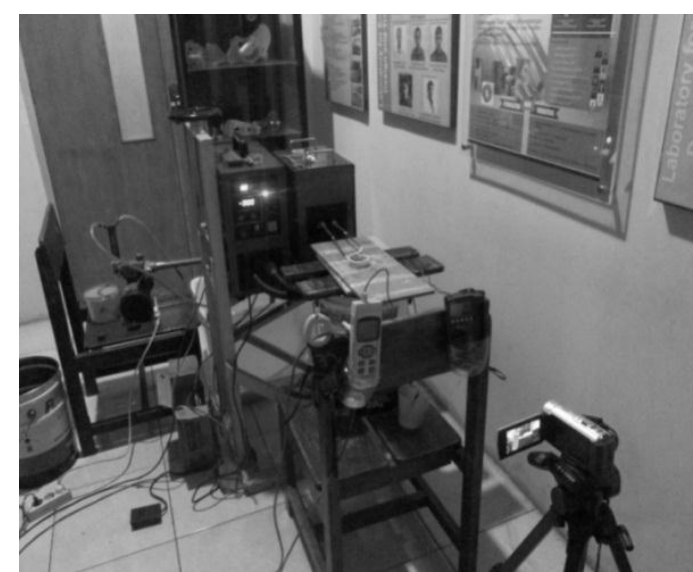

Gambar 2. Rangkaian mesin pemanas induksi

Pada pengujian ini digunakan tiga jenis koil pemanas, yaitu koil dua lilitan, koil tiga lilitan dan koil tempering. Koil yang digunakan terbuat dari pipa tembaga dengan diameter 5 $\mathrm{mm}$ dan tebal $1 \mathrm{~mm}$. Gambar koil pemanas dapat dilihat pada Gambar 3.

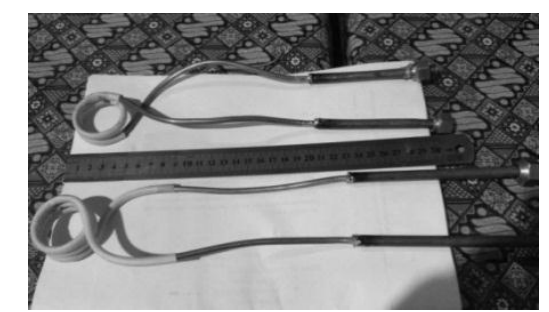

Gambar 3 Koil pemanas quenching

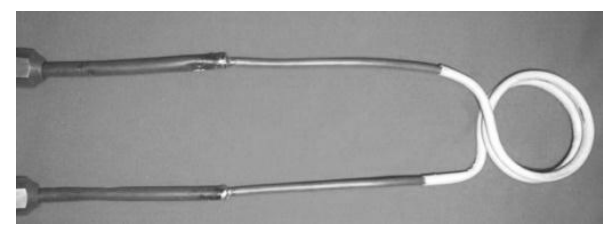

Gambar 4 Koil pemanas tempering 


\section{Bahan}

Bahan yang digunakan dalam pengujian ini adalah baja AISI 1045 dengan dimensi awal pin track link bulldozer seperti pada gambar 5.
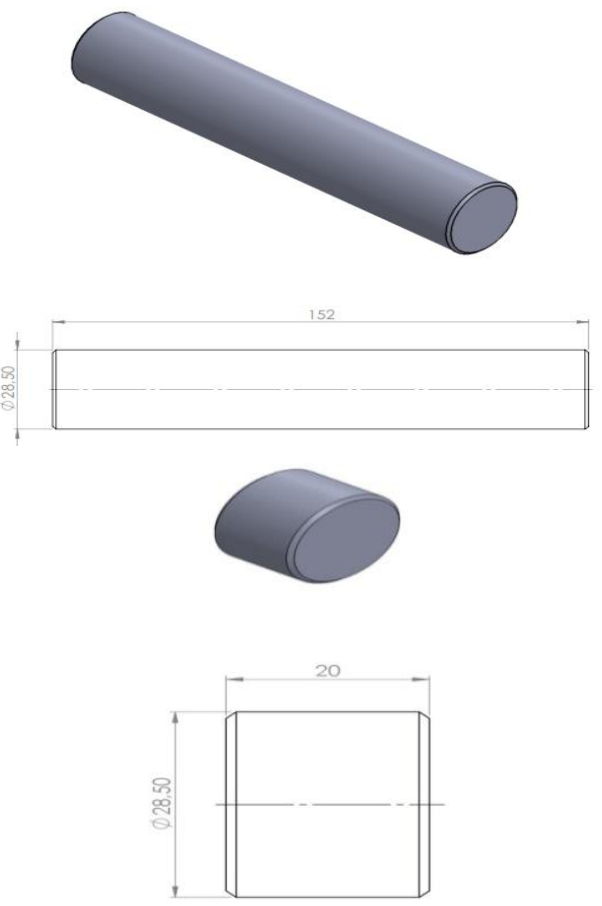

Gambar 5. Bentuk dan dimensi spesimen uji

\section{HASIL DAN PEMBAHASAN}

Komposisi bahan

Tabel 2 Komposisi unsur pin track link bulldozer

\begin{tabular}{cc}
\hline Unsur & $\begin{array}{c}\text { Persentase } \\
\text { kandungan }(\%)\end{array}$ \\
\hline $\mathrm{Fe}$ & 97,572 \\
$\mathrm{~S}$ & 0,021 \\
$\mathrm{Al}$ & 0,0024 \\
$\mathrm{C}$ & 0,426 \\
$\mathrm{Ni}$ & 0,0513 \\
$\mathrm{Nb}$ & 0,0009 \\
$\mathrm{Si}$ & 0,243 \\
$\mathrm{Cr}$ & 0,2648 \\
$\mathrm{Mn}$ & 1,159 \\
$\mathrm{Mo}$ & 0,0061 \\
$\mathrm{P}$ & 0,0162 \\
$\mathrm{Cu}$ & 0,175 \\
$\mathrm{Ti}$ & 0,0129 \\
$\mathrm{~N}$ & 0,018 \\
$\mathrm{~B}$ & 0,0006 \\
$\mathrm{~Pb}$ & $-0,00$ \\
$\mathrm{Sb}$ & 0,0038 \\
$\mathrm{Ca}$ & 0,0019 \\
$\mathrm{Mg}$ & $-0,0011$ \\
$\mathrm{Zn}$ & 0,0022 \\
$\mathrm{Co}$ & 0,0066 \\
\hline
\end{tabular}

Berdasarkan Tabel 2 dapat diketahui bahwa material spesimen pintrack link bulldozer memiliki kandungan Fe sebesar 97,57 $\%$ dan $\mathrm{C}$ sebesar 0,426\%. Dengan diketahuinya kedua unsur tersebut, maka raw material dari pin track link bulldozer dapat diklasifikasikan sebagai baja karbon sedang karena baja karbon sedang memilki kadar karbon antara 0,25-0,60 $\%$.

\section{Persebaran nilai kekerasan}

Spesimen pin track link bulldozer dapat ditunjukkan pada Gambar 6.

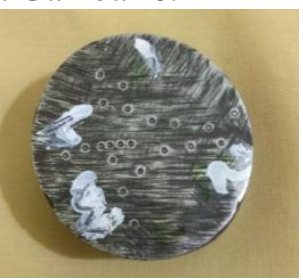

\section{Gambar 6. pin track link bulldozer}

Nilai kekerasan dari pin track link bulldozer bekas dari diameter luar ke dalam adalah 50, 5 HRC; 40 HRC; 34,6 HRC; 30,6; 28,25 HRC dan 28 HRC.

Sedangkan gambar specimen yang telah diuji kekerasannya diperlihatkan pada Gambar 7.
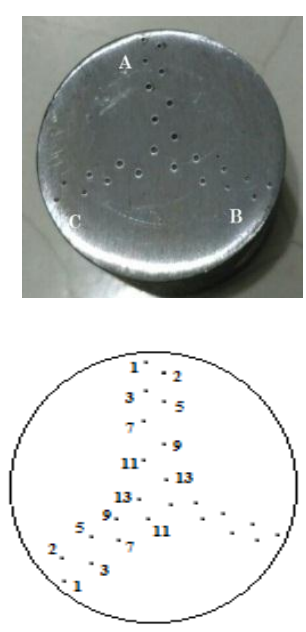

Gambar 7. Persebaran titik indentasi dalam mm dari tepi pada AISI 1045 sebagai material pengganti pin track link bulldozer

Dari hasil pengukuran masing-masing specimen dari tempering $250,300,350{ }^{\circ} \mathrm{C}$ didapatkan yang paling mirip dengan pin track link bulldozer bekas adalah specimen tempering $350{ }^{\circ} \mathrm{C}$ yang diberi nama SP 4.3. Untuk hasil tempering 250 dan $300{ }^{\circ} \mathrm{C}$ didapatkan maksimum kekerasan 49 HRC. Dan 
paling jaur dari diameter luar adalah 36 HRC. Sedangkan pada specimen tempering $350{ }^{\circ} \mathrm{C}$ bagian tepi mendekati diameter luar diatas 50 HRC.

Dari perbandingan antara nilai kekerasan quenching dengan nilai kekerasan tempering dapat disimpulkan penurunan kekerasan yang signifikan terjadi pada spesimen 4.3 tempering dengan suhu tempering $350{ }^{\circ} \mathrm{C}$. Nilai kekerasan maksimum rerata dari diameter luar spesimen sebelum tempering adalah 59,5 HRC dan sesudah di tempering turun menjadi 50,1 HRC. Semakin tinggi suhu tempering, kekerasan akan menjadi lebih rendah.

Hasil uji kekerasan dapat dibuat grafik yang disaikan pada Gambar 8

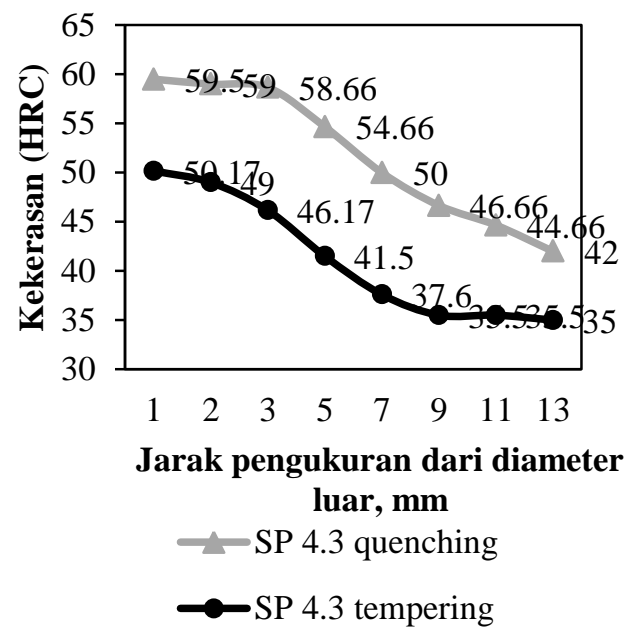

Gambar 8. Grafik spesimen 4.3 setelah quenching dan tempering

\section{Hasil foto mikro}

Spesimen pin track link bulldozer

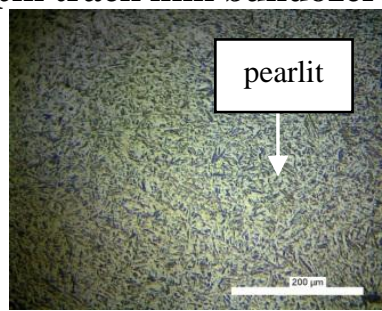

(a)

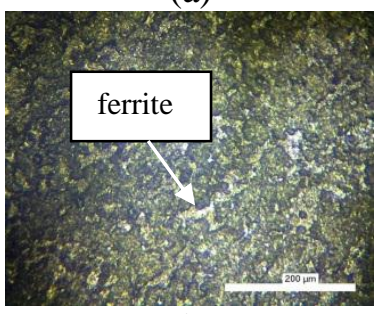

(b)
Gambar 9. (a) bagian tepi (b) bagian tengah Struktur mikro spesimen pin track link bulldozer

Spesimen 43 setelah quenching

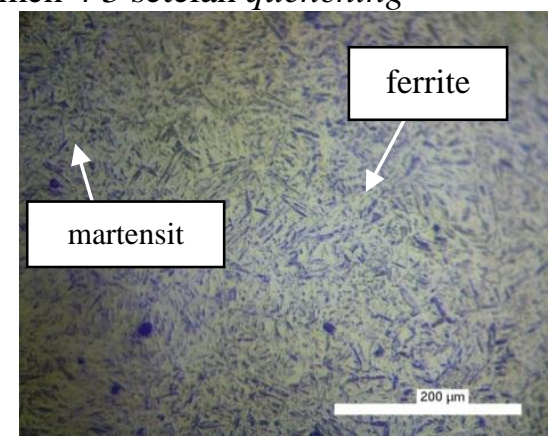

(a)

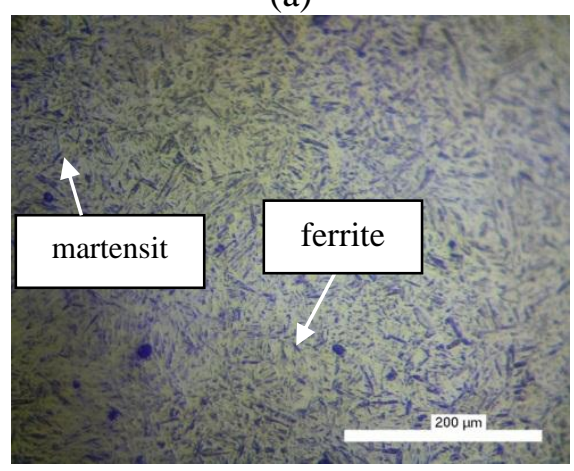

(b)

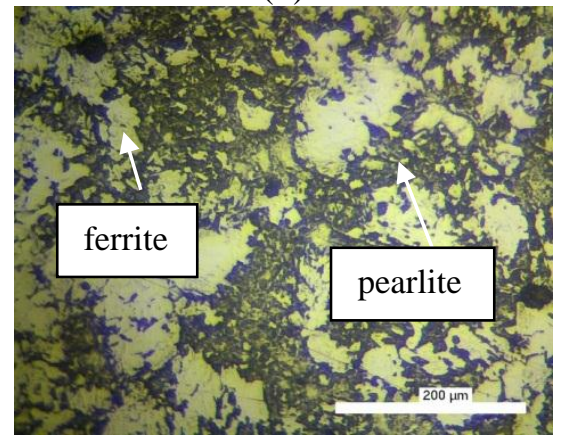

(c)

Gambar 10. Struktur mikro spesimen 4.3 setelah quenching (a) bagian tepi (b) bagian tengah (c) bagian dalam perbesaran 200x

Spesimen 4.3 setelah tempering

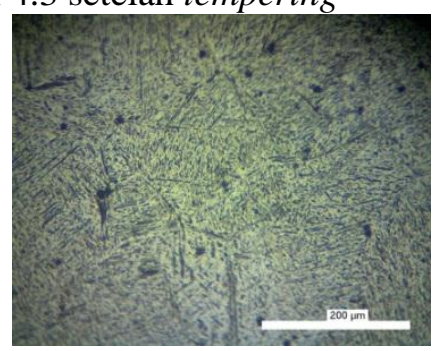

(a) 


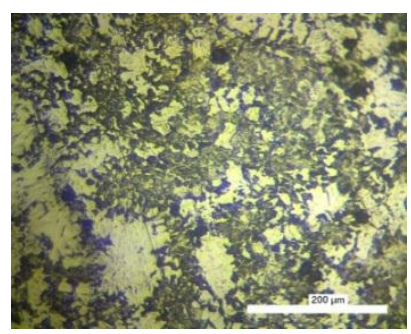

(b)

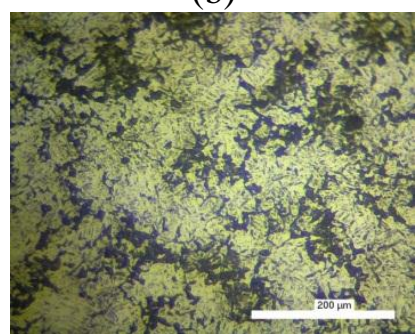

Gambar 11 Struktur mikro spesimen 4.3 setelah tempering $350{ }^{\circ} \mathrm{C}$ (a) bagian tepi (b) bagian tengah (c) bagian dalam perbesaran 200x

Terbentuknya fasa martensit pada bagian tepi dan tengah ini menyebabkan kenaikan kekerasan pada bagian tersebut. dimana kekerasan bagian tepi spesimen 4.3 mencapai 49,5 HRC dan mengalami penurunan kekerasan mencapai 35 HRC. Pada Gambar 11 dapat dilihat bahwa struktur mikro pada bagian tengah mengalami perubahan hilangnya fasa martensit.

\section{KESIMPULAN}

1. Struktur mikro pada material pin track link bulldozer memperlihatkan struktur martensit pada jarak $1 \mathrm{~mm}-3 \mathrm{~mm}$ dari tepi spesimen dan struktur pearlite, ferrite pada tengah spesimen sedangkan nilai kekerasan dari tepi spesimen sampai ke tengah mengalami penurunan yaitu nilai rerata 50,5 HRC pada jarak $1 \mathrm{~mm}$ dari tepi spesimen dan 28 HRC pada jarak $14 \mathrm{~mm}$ dari tepi spesimen.

2. Nilai kekerasan maksimum pada proses tempering sebesar 49 HRC dicapai pada suhu $350{ }^{\circ} \mathrm{C}$ dan penurunan kekerasan ratarata sebesar 1-2 HRC pada temperatur 250 ${ }^{\circ} \mathrm{C}, 2-5$ HRC pada temperatur $300{ }^{\circ} \mathrm{C}$ dan 5-11 HRC pada temperatur $350^{\circ} \mathrm{C}$.

3. Struktur mikro pada spesimen pin material AISI 1045 sebagai pengganti pin track link bulldozer pada proses tempering pada suhu $250{ }^{\circ} \mathrm{C}$ memperlihatkan struktur martensit pada tepi dan tengah, pada bagian dalam memperlihatkan struktur pearlite, ferrite. Sedangkan tempering pada suhu $300{ }^{\circ} \mathrm{C}$ dan $350 \quad{ }^{\circ} \mathrm{C}$ memperlihatkan struktur martensit pada jarak $1 \mathrm{~mm}-3 \mathrm{~mm}$ dari tepi spesimen, tengah pada jarak $5 \mathrm{~mm}-9$ $\mathrm{mm}$ dan dalam pada jarak $11 \mathrm{~mm}-14 \mathrm{~mm}$ dari tepi spesimen memperlihatkan struktur pearlite, ferrite.

\section{Saran}

Dalam melakukan induction hardening diperlukan alat ukur yang presisi untuk mengukur ketepatan suhu pada saat pengujian.

\section{DAFTAR PUSTAKA}

A.P.Bayuseno E, E Yohana, M. Dzulfikar. D I Prasetyo, M. Khadif dan R.ismail M, 2014,Pengaruh Tempering Menggunakan Pemanas Induksi Terhadap Nilai Kekerasan Dan Struktur Mikro Material Baja St 60 Pasca Quenching,SNTMUT, Hal 01-5, ISBN: 978-602-70012-0-6.

Amanto, H, 1999,Ilmu Bahan, Bumi Aksara, Jakarta.

Avner H S, 1974, Introduction To Physical Metallurgy, Mcgraw-Hill International edition, New york.

Dalil, M. Priyatno, A. Inoun I, 1999, Pengaruh Perbedaan Waktu Penahanan Suhu Stabil (Holding Time) Terhadap Kekerasan Logam. Jurnal Natur Indonesia, Vol.II No 1. Hal 12-17.

Kurniawan P., 2007,Perbedaan Nilai Kekerasan pada Proses Double Hardening dengan Media Pendingin Air dan Oli SAE 20 pada Baja Karbon, (Skripsi), Universitas Negeri Semarang, Semarang.

Mizhar, S. d, 2011, Pengaruh Perbedaan Kondisi Tempering Terhadap Struktur Mikro dan Kekerasan dari Baja AISI 4140. Jurnal Dinamis, vol. II No.8. ISSN 0216-7492.

Pama,2003, Sistem Final Drive And Undercarriage, PT.Pama Persada Nusantara, Jakarta.

Schonmentz G, 1985, Pengetahuan Bahan Dalam Pengerjaan Logam, Aksara.

Supardi E. 1999,Pengujian Logam, Angkasa, Bandung.

Syaefudin, 2001,Pengerasan Baja karbon rendah dengan Metode Nitridasi dan Quenching, (Skripsi), Universitas Diponegoro, Semarang.

Thelning K.E, 1984, Steel And Its Heat Treatment Second Edition, Butterwoth, London. 
V. Rudnev D. L. 2003,Handbook of Induction Heating, Marcel Dekker Inc, USA.

Yogantoro A, 2010,Penelitian Pengaruh Variasi Temperatur Pemanasan Low Tempering, Medium Tempering dan High Tempering pada MediuCarbon Steel
Produksi Pengecoran terhadap Struktur Mikro,Kekerasan dan Ketangguhan, (Skripsi), UMS, Surakarta.

Zinn S a, 1988, Element of Induction Heating Design Control and Application, ASM International. 